\title{
Subacute Combined Degeneration Caused by Nitrous Oxide Intoxication: A Report of Two Cases
}

\author{
Cheol Choi, MD' ${ }^{1}$, Taehee Kim, MD ${ }^{1}$, Ki Deok Park, MD, PhD ${ }^{2}$, Oh Kyung Lim, MD, PhD ${ }^{2}$, Ju Kang Lee, MD, PhD
}

${ }^{1}$ Department of Rehabilitation Medicine, Gil Medical Center, Incheon; ${ }^{2}$ Department of Rehabilitation Medicine, Gil Medical Center, Gachon University College of Medicine, Incheon, Korea

\begin{abstract}
We report two cases of subacute combined degeneration (SCD) caused by nitrous oxide $\left(\mathrm{N}_{2} \mathrm{O}\right)$ gas intoxication, which is rarely reported in Korea. Two patients recreationally inhaled $\mathrm{N}_{2} \mathrm{O}$ gas daily for several months. They presented with paresthesia of limbs, voiding difficulty, and gait disturbance. The initial vitamin $\mathrm{B}_{12}$ levels were normal or decreased, but homocysteine levels of the two patients were increased. Magnetic resonance imaging of the cervical spine showed T2-weighted hyperintensity in the bilateral dorsal columns of the cervical spinal cord. Electromyography and somatosensory evoked potential tests for both patients suggested posterior column lesion of the spinal cord combined with sensorimotor polyneuropathy. According to these findings, we concluded that the two patients had SCD. The patient's symptoms partially improved after cessation of $\mathrm{N}_{2} \mathrm{O}$ gas inhalation and the receiving of vitamin $B_{12}$ supplementation therapy. As the incidence of recreational $\mathrm{N}_{2} \mathrm{O}$ gas inhalation is increasing in Korea, physicians must be alert to the $\mathrm{N}_{2} \mathrm{O}$ induced SCD in patients presenting with progressive myelopathy.
\end{abstract}

Keywords Nitrous oxide, Subacute combined degeneration, Vitamin B12

\section{INTRODUCTION}

Nitrous oxide $\left(\mathrm{N}_{2} \mathrm{O}\right)$ is frequently used as an analgesic during dental procedures, but it is often misused overseas for recreation [1]. $\mathrm{N}_{2} \mathrm{O}$ inactivates active vitamin $\mathrm{B}_{12}$, which is a cofactor for methionine synthase that methylated myelin sheath phospholipids [2]. Therefore, overuse of $\mathrm{N}_{2} \mathrm{O}$ can lead to a decrease in active vitamin $\mathrm{B}_{12}$ and, ultimately, to the demyelination of the central and peripheral nervous systems [2].
Subacute combined degeneration (SCD) is a condition with combined myelopathy and peripheral neuropathy, mostly caused by vitamin $B_{12}$ deficiency [1]. Severe deficiency of vitamin $B_{12}$ can lead to axonal loss in the posterolateral column of the spinal cord and cause symptoms such as ataxia, paresthesia, and muscular weakness $[3,4]$.

We report two cases of SCD due to daily recreational $\mathrm{N}_{2} \mathrm{O}$ inhalation over several months, which is rare in Korea. org/0000-0003-1684-4737); Oh Kyung Lim (http://orcid.org/0000-0002-4286-8073); Ju Kang Lee (http://orcid.org/0000-0002-8335-9785).

(c) This is an open-access article distributed under the terms of the Creative Commons Attribution Non-Commercial License (http://creativecommons.org/ licenses/by-nc/4.0) which permits unrestricted noncommercial use, distribution, and reproduction in any medium, provided the original work is properly cited. Copyright (C) 2019 by Korean Academy of Rehabilitation Medicine 


\section{CASE REPORTS}

\section{Case 1}

A 24-year-old male was admitted to the emergency center with paresthesia of all limbs, voiding difficulty, and gait disturbance for 1 month. The patient did not have a significant medical illness or any medication abuse history. However, the patient had a 5-month history of daily recreational $\mathrm{N}_{2} \mathrm{O}$ inhalation.

Manual muscle test (MMT) of all limbs was normal. Light touch, proprioception, temperature, and pain sensory examinations were normal, but deep touch sensation of the patient's feet was decreased. Moreover, the patient stated that he felt as if he was walking on sand when he attempted mobility. He complained of paresthesia and showed an ataxic gait. The Romberg test was positive, and tandem gait could not be performed properly. Deep tendon reflexes were hyperreflexic at all four limbs. The Hoffmann and Babinski signs were not present.

The patient blood tests showed hemoglobin $13.1 \mathrm{~g} / \mathrm{dL}$ (normal range, $13-17 \mathrm{~g} / \mathrm{dL}$ ); red blood cell count $3.54 \times 10^{6} /$ $\mathrm{mm}^{3}\left(4.3-5.6 \times 10^{6} / \mathrm{mm}^{3}\right)$; mean corpuscular volume 103.7 fL (83-99 fL); mean corpuscular hemoglobin 37 pg (28-34 pg); vitamin $B_{12}$ (cobalamin) 308 pg/mL (211-911 pg/ $\mathrm{mL})$, homocysteine $45.23 \mu \mathrm{mol} / \mathrm{L}(5-15 \mu \mathrm{mol} / \mathrm{L})$. Brain magnetic resonance imaging (MRI) was normal, but T2weighted MRI of the cervical spine showed inverted Vshaped hyperintensity in the bilateral dorsal columns over the entire cervical spinal cord (Fig. 1). Based on the patient's symptoms, blood test results and MRI findings, he was diagnosed with SCD. For the treatment, he received daily injections of vitamin $B_{12} 1 \mathrm{mg}$ over 1 week. Serum vitamin $B_{12}$ level subsequently increased to over
20,000 pg/mL.

An electrodiagnostic study was performed approximately 6 weeks from the onset of symptoms. Sensory nerve conduction studies showed delayed peak latencies of bilateral sural and superficial peroneal sensory nerve action potentials (SNAP). Motor nerve conduction studies showed delayed onset latencies of bilateral tibial compound muscle action potentials (CMAP), and decreased conduction velocities of tibial nerve (Table 1). SNAPs and CMAPs of bilateral upper extremities were normal. The H-reflex measured in gastrocnemius muscle was bilaterally unreactive. N20 and P37 latencies were delayed in median and tibial somatosensory evoked potentials (SEP), bilaterally (Table 2). A needle electromyography (EMG) study showed normal insertional activities and motor unit potentials in all limb and paraspinal muscles. These electrodiagnostic findings were consistent with the posterior column lesion of the cervical spinal cord and the sensorimotor polyneuropathy of the lower limbs.

The patient received additional intramuscular vitamin $\mathrm{B}_{12}$ injections at the outpatient clinic. The paresthesia was shown to have improved, but which of the hands and feet were remained. Voiding difficulty improved completely, but the ataxia improved partially after cessation of $\mathrm{N}_{2} \mathrm{O}$ gas inhalation and the subsequent addition of vitamin $B_{12}$ supplement therapy.

\section{Case 2}

A 22-year-old female presented with paresthesia and weakness of bilateral lower extremities, and voiding difficulty 2 days before she visited the emergency center. One year ago, the patient was diagnosed with $\mathrm{N}_{2} \mathrm{O}$ induced SCD. At that time, she had presented paresthesia
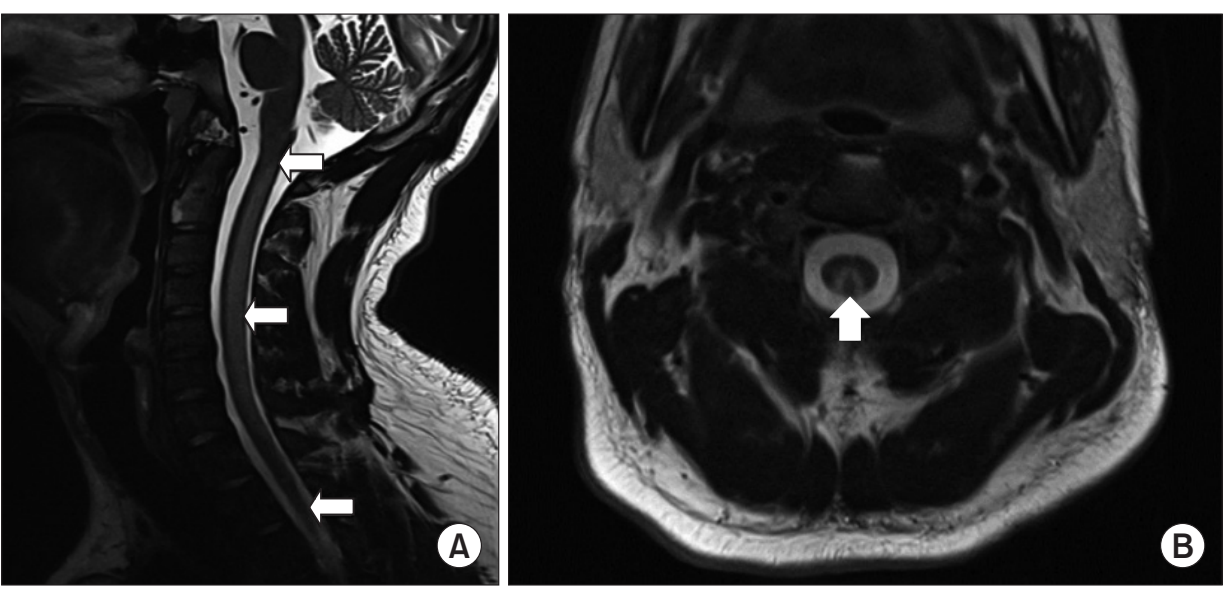

Fig. 1. In case 1, the cervical spine T2-weighted magnetic resonance imaging showed an inverted Vshaped hyperintensity (arrow) in the bilateral dorsal column of cervical spinal cord: (A) sagittal view and (B) axial view at C2 level. 
Table 1. Results of the nerve conduction study

\begin{tabular}{|c|c|c|c|c|c|c|c|c|c|c|c|c|}
\hline \multirow{3}{*}{ Nerve } & \multicolumn{6}{|c|}{ Case 1} & \multicolumn{6}{|c|}{ Case 2} \\
\hline & \multicolumn{2}{|c|}{ Latency (ms) } & \multicolumn{2}{|c|}{ Amplitude } & \multicolumn{2}{|c|}{$\mathrm{CV}(\mathrm{m} / \mathrm{s})$} & \multicolumn{2}{|c|}{ Latency (ms) } & \multicolumn{2}{|c|}{ Amplitude } & \multicolumn{2}{|c|}{$\mathrm{CV}(\mathrm{m} / \mathrm{s})$} \\
\hline & $\mathbf{R t}$ & Lt & Rt & Lt & Rt & Lt & Rt & Lt & Rt & Lt & Rt & Lt \\
\hline \multicolumn{13}{|l|}{ Sensory } \\
\hline Sural & 4.38 & 4.06 & 16.4 & 16.7 & & & 5.47 & 4.38 & 6.7 & 3.1 & & \\
\hline SPN & 3.59 & 3.59 & 11.0 & 10.9 & & & 10.36 & 8.07 & 5.3 & 7.7 & & \\
\hline \multicolumn{13}{|l|}{ Motor } \\
\hline \multicolumn{13}{|l|}{ Peroneal } \\
\hline Ankle & 5.42 & 6.15 & 2.4 & 1.7 & & & NR & NR & NR & NR & & \\
\hline Fib head & 15.73 & 16.51 & 1.9 & 1.6 & 37.8 & 37.6 & NR & NR & NR & NR & & \\
\hline \multicolumn{13}{|l|}{ Tibial } \\
\hline Ankle & 6.20 & 6.41 & 10.7 & 12.7 & & & NR & NR & NR & NR & & \\
\hline Knee & 17.35 & 17.08 & 9.0 & 9.1 & 38.6 & 39.3 & NR & NR & NR & NR & & \\
\hline
\end{tabular}

Abnormal values are represented in bold.

Amplitudes are measured in microvolt ( $\mu \mathrm{V}$, sensory) and in millivolt ( $\mathrm{mV}$, motor).

$\mathrm{CV}$, conduction velocity; Rt, right; Lt, left; SPN, superficial peroneal nerve; Fib, fibular; NR, no response.

Table 2. Results of the somatosensory evoked potentials

\begin{tabular}{|c|c|c|c|c|c|c|c|c|c|c|c|c|}
\hline \multirow{4}{*}{ Nerve } & \multirow{2}{*}{\multicolumn{4}{|c|}{$\begin{array}{l}\text { Case } 1 \\
\text { Initial }\end{array}$}} & \multicolumn{8}{|c|}{ Case 2} \\
\hline & & & & & \multicolumn{4}{|c|}{ Initial } & \multicolumn{4}{|c|}{ After 3 months } \\
\hline & \multicolumn{2}{|c|}{ N20 (ms) } & \multicolumn{2}{|c|}{ P37 (ms) } & \multicolumn{2}{|c|}{ N20 (ms) } & \multicolumn{2}{|c|}{ P37 (ms) } & \multicolumn{2}{|c|}{ N20 (ms) } & \multicolumn{2}{|c|}{ P37 (ms) } \\
\hline & Rt & Lt & $\mathbf{R t}$ & Lt & Rt & Lt & Rt & Lt & Rt & Lt & Rt & Lt \\
\hline Median & 25.31 & 22.71 & & & 26.82 & 26.20 & & & 23.90 & 23.13 & & \\
\hline Tibial & & & 45.10 & 46.25 & & & 53.02 & 50.21 & & & 36.04 & 36.35 \\
\hline
\end{tabular}

Abnormal values are represented in bold.

Rt, right; Lt, left.

of all limbs, voiding difficulty, and had a gait disturbance. Although she had been treated with vitamin $\mathrm{B}_{12}$ supplements, paresthesia of lower limbs had been remained.

The patient did not have a medication abuse history, but she inhaled $\mathrm{N}_{2} \mathrm{O}$ gas again daily for 3 months. Paresthesia of bilateral lower limbs was aggravated, and she could not walk alone due to lower limb weakness. Also, she had voiding difficulty.

The MMT of the upper extremities was normal, but that of the lower extremities was reduced to grade 2 . The temperature and pain sensation were intact. The light touch sensation of bilateral lower extremities was decreased. The proprioception of all limbs was impaired. The deep tendon reflexes of upper extremities were normal, but were absent in lower extremities. The Hoffmann and Babinski signs were not present. Neither the Romberg nor tandem gait tests could be performed because the patient was not able to walk alone.

The initial blood tests showed no anemia; hemoglobin $12.9 \mathrm{~g} / \mathrm{dL}$ (normal range, 11.5-15.5 g/dL); red blood cell count, $3.86 \times 10^{6} / \mathrm{mm}^{3}\left(3.8-5.0 \times 10^{6} / \mathrm{mm}^{3}\right)$; mean corpuscular volume, $96.6 \mathrm{fL}$ (83-99 fL); mean corpuscular hemoglobin $33.4 \mathrm{pg}$ (27-33 pg). The level of vitamin $\mathrm{B}_{12}$ (cobalamin) was $70 \mathrm{pg} / \mathrm{mL}(211-911 \mathrm{pg} / \mathrm{mL})$ and the level of homocysteine was over $130 \mu \mathrm{mol} / \mathrm{L}(5-15 \mu \mathrm{mol} / \mathrm{L})$. The T2-weighted MRI of the cervical spine performed 1 year ago showed a hyperintensity between the 3rd and 5th cervical spinal cord, although MRI was not performed at this time of admission.

Two weeks after symptom onset, an electrodiagnostic study was performed. The study showed delayed peak latencies of bilateral sural and superficial peroneal SNAPs. There was no response in bilateral tibial and peroneal CMAPs (Table 1). SNAPs and CMAPs of upper extremi- 
Table 3. Results of the needle electromyography in case 2

\begin{tabular}{lcccccccc}
\hline \multirow{2}{*}{ Muscle } & \multicolumn{2}{c}{ Fib } & \multicolumn{2}{c}{ PSW } & \multicolumn{2}{c}{ MUAP } & \multicolumn{2}{c}{ Recruitment } \\
\cline { 2 - 9 } & Rt & Lt & Rt & Lt & Rt & Lt & Rt & Lt \\
\hline Tibialis anterior & $\mathbf{3 +}$ & $\mathbf{3 +}$ & $\mathbf{3 +}$ & $\mathbf{3 +}$ & Normal & Normal & Discrete & Discrete \\
Peroneus longus & $\mathbf{3 +}$ & $\mathbf{3 +}$ & $\mathbf{3 +}$ & $\mathbf{3 +}$ & Normal & Normal & Discrete & Discrete \\
Gastrocnemius & $\mathbf{3 +}$ & $\mathbf{3 +}$ & $\mathbf{3 +}$ & $\mathbf{3 +}$ & Normal & Normal & Discrete & Discrete \\
Vastus medialis & - & - & - & - & Normal & Normal & Reduced & Reduced \\
Tensor fasciae latae & - & - & - & - & Normal & Normal & Reduced & Reduced \\
Lumbar paraspinals & - & - & - & - & NC & NC & NC & NC \\
\hline
\end{tabular}

Abnormal values are represented in bold.

MUAP, motor unit action potential; Fib, fibrillation; PSW, positive sharp wave; Rt, right; Lt, left; NC, not checkable.

ties were normal. Bilateral H-reflexes of the tibial nerve were absent. In bilateral median and tibial SEP, N20 and P37 latencies were delayed (Table 2). A needle EMG study showed increased insertion activities and abnormal spontaneous activities in the bilateral tibialis anterior, peroneus longus, and gastrocnemius. Recruitment patterns of lower extremities were reduced (Table 3).

The patient received intramuscular $1 \mathrm{mg}$ injections of vitamin $\mathrm{B}_{12}$ daily for 7 days, and every week for 3 weeks during hospitalization. The paresthesia of lower limbs improved. However, the voiding difficulty did not improve and an indwelling urinary catheter had to be maintained. The weakness of the bilateral lower extremities did not improve.

The patient received additional $1 \mathrm{mg}$ intramuscular injections of vitamin $B_{12}$ every week for 2 weeks, and every 2 weeks for 4 weeks in an outpatient clinic. Three months after the previous EMG study, the proprioception of upper limbs was normal and also improved in lower limbs. The paresthesia of lower limbs further improved. The MMT of lower limbs improved from grade 2 to 3 , and she was able to walk under the assistance of others. Voiding difficulty also partially improved and her indwelling urinary catheter was therefore removed.

A follow-up electrodiagnostic study was conducted at the outpatient clinic. The N20 latencies of bilateral median SEPs were decreased compared to the previous study, but was still not noted to be within the normal range. The P37 latencies of the bilateral tibial SEPs were recovered to normal. These results suggest that the cervical myelopathy was improving compared to the previous EMG study.

Written informed consents were obtained.

\section{DISCUSSION}

Vitamin $B_{12}$ deficiency is the cause of subacute combined degeneration [1]. The main symptoms of SCD are neurologic deficits including paresthesia of the limbs, muscle weakness, and loss of position and vibratory sensations [4]. In most cases, Vitamin $B_{12}$ deficiency is usually caused by malnutrition, deficiency in intrinsic factor, and Crohn's disease [1]. Inactivation of vitamin $B_{12}$ due to $\mathrm{N}_{2} \mathrm{O}$ inhalation is also a potential etiological factor [1].

$\mathrm{N}_{2} \mathrm{O}$ inactivates vitamin $\mathrm{B}_{12}$ by changing it from its active monovalent form to its inactive, bivalent form. Active vitamin $B_{12}$ is a coenzyme of methionine synthase, the enzyme involved in the synthesis of DNA, RNA, and myelin [5]. Therefore, inactive vitamin $B_{12}$ inhibits myelin synthesis and leads to demyelination, axonal swelling, and, ultimately, axonal loss [1]. Depending on the supplementation of vitamin $\mathrm{B}_{12}$ and the amount of $\mathrm{N}_{2} \mathrm{O}$ inhaled, the level of vitamin $\mathrm{B}_{12}$ can be low, normal, or high [5]. SCD may also occur with normal vitamin $B_{12}$ level, since $\mathrm{N}_{2} \mathrm{O}$ inactivates cobalamin to reduce the amount of functional cobalamin [6]. Homocysteine, a substrate necessary for vitamin $B_{12}$ to act as a methionine synthase cofactor, increases with vitamin $B_{12}$ deficiency [5]. It was shown that the initial vitamin $B_{12}$ level was normal in case 1 , but was decreased in case 2 . The homocysteine levels in both cases were elevated due to a deficiency in active vitamin $\mathrm{B}_{12}$.

Treatment for SCD due to $\mathrm{N}_{2} \mathrm{O}$ inhalation is a cessation of $\mathrm{N}_{2} \mathrm{O}$ inhalation and the supplement of vitamin $\mathrm{B}_{12}$ [1]. The traditional method for vitamin $B_{12}$ supplementation is intramuscular injection of $1 \mathrm{mg}$ vitamin $B_{12}$ daily for the first week, $1 \mathrm{mg}$ injections of vitamin $B_{12}$ weekly for the next 4 weeks, followed by $1 \mathrm{mg}$ monthly injections 
for life until the underlying cause is eliminated [7]. The speed of recovery after treatment may vary according to the degree of damage to the spinal cord [1]. If there is no sensory loss, and the Romberg test and Babinski sign are negative, the rate of recovery is expected to be higher [8]. Among 18 cases of $\mathrm{N}_{2} \mathrm{O}$ induced myeloneuropathy with subclinical vitamin $\mathrm{B}_{12}$ deficiency, 15 patients showed improvement of symptoms and only 4 patients showed complete resolution of symptoms [9].

In case 1 , the patient received daily intramuscular vitamin $B_{12}$ injections for 1 week after admission and weekly $1 \mathrm{mg}$ injections for 3 weeks in an outpatient clinic after discharge. An EMG was performed after 9 injections of vitamin $B_{12}$, and the patient's symptoms had partially improved. A limitation of this study was that the EMG was not performed early. We could not assess the degree of neural recovery through additional EMG or MRI due to the patient's failure to visit outpatient clinics. Moreover, the proprioception examination was normal based on joint position sense test, but the position sense of the lower limb seemed abnormal during walking because of the hypesthesia and paresthesia.

These two cases can be diagnosed as SCD based on the history of $\mathrm{N}_{2} \mathrm{O}$ abuse, typical neurologic symptoms and signs as well as the compatible results of MRI, EMG, SEP, and blood test. Symptoms improved with vitamin $B_{12}$ therapy and cessation of $\mathrm{N}_{2} \mathrm{O}$ gas inhalation.

In Korea, there was only one prior case report of myeloneuropathy after chronic $\mathrm{N}_{2} \mathrm{O}$ abuse [10]. Although the report includes an electrodiagnostic study of case, there were no detailed data. We confirmed the nerve damage of our two patients throughout the electrodiagnostic study including needle EMG. The findings of case 1 were primarily demyelinating status (neurapraxia), and the case 2 results were axonal involvement status (axonotmesis). The results of case 2 were shown to have been more severe than with case 1 . We found that the severity of symptoms and recovery rate were correlated with the EMG results.

Recently $\mathrm{N}_{2} \mathrm{O}$ gas was sold under the name 'narcotic balloon' or 'happy balloon'. It arouses concerns for abuse in population. Therefore, physicians must be alert to the $\mathrm{N}_{2} \mathrm{O}$ induced SCD in patients presenting with progressive myelopathy. When SCD is diagnosed, vitamin $B_{12}$ should be supplemented promptly for a good prognosis of neurological recovery.

\section{CONFLICT OF INTEREST}

No potential conflict of interest relevant to this article was reported.

\section{AUTHOR CONTRIBUTION}

Conceptualization: Kim T, Lee JK. Visualization: Choi C. Writing - original draft: Choi C, Kim T. Writing - review and editing: Lee JK, Lim OK, Park KD. Approval of final manuscript: all authors.

\section{REFERENCES}

1. Lin RJ, Chen HF, Chang YC, Su JJ. Subacute combined degeneration caused by nitrous oxide intoxication: case reports. Acta Neurol Taiwan 2011;20:129-37.

2. Hsu CK, Chen YQ, Lung VZ, His SC, Lo HC, Shyu HY. Myelopathy and polyneuropathy caused by nitrous oxide toxicity: a case report. Am J Emerg Med 2012;30:1016. 3-6.

3. Katsaros VK, Glocker FX, Hemmer B, Schumacher M. MRI of spinal cord and brain lesions in subacute combined degeneration. Neuroradiology 1998;40:716-9.

4. Timms SR, Cure JK, Kurent JE. Subacute combined degeneration of the spinal cord: MR findings. AJNR Am J Neuroradiol 1993;14:1224-7.

5. Shoults K. Case report: neurological complications of nitrous oxide abuse. B C Med J 2016;58:192-4.

6. Pema PJ, Horak HA, Wyatt RH. Myelopathy caused by nitrous oxide toxicity. AJNR Am J Neuroradiol 1998;19:894-6.

7. Ozkan FU, Kaysin MY, Boy FN, Ustun I, Aktas I. Progressive subacute combined degeneration: a severe relapse with dis-continuation of vitamin B12 treatment. Turk J Phys Med Rehabil 2016;62:369-72.

8. Vasconcelos OM, Poehm EH, McCarter RJ, Campbell WW, Quezado ZM. Potential outcome factors in subacute combined degeneration: review of observational studies. J Gen Intern Med 2006;21:1063-8.

9. Singer MA, Lazaridis C, Nations SP, Wolfe GI. Reversible nitrous oxide-induced myeloneuropathy with pernicious anemia: case report and literature review. Muscle Nerve 2008;37:125-9.

10. Kwoun YJ, Choi YJ, Oh JY, Park KD, Choi KG. Myeloneuropathy following chronic abuse of nitrous oxide. J Korean Neurol Assoc 2003;21:432-5. 